University of Wollongong

Research Online

Faculty of Engineering and Information

Faculty of Engineering and Information

Sciences - Papers: Part B

Sciences

2019

Comprehensive Analysis of the Effect of Ausforming on the Martensite Start Temperature in a Fe-C-Mn-Si Medium-Carbon High-Strength Bainite Steel

\author{
Junyu Tian \\ Wuhan University of Science and Technology \\ Guanghui Chen \\ Wuhan University of Science and Technology \\ Yaowen Xu \\ Wuhan University of Science and Technology \\ Zhengyi Jiang \\ University of Wollongong, jiang@uow.edu.au \\ Guang Xu \\ Wuhan University of Science and Technology
}

Follow this and additional works at: https://ro.uow.edu.au/eispapers1

Part of the Engineering Commons, and the Science and Technology Studies Commons

Research Online is the open access institutional repository for the University of Wollongong. For further information contact the UOW Library: research-pubs@uow.edu.au 


\title{
Comprehensive Analysis of the Effect of Ausforming on the Martensite Start Temperature in a Fe-C-Mn-Si Medium-Carbon High-Strength Bainite Steel
}

\author{
Abstract \\ The comprehensive effect of strain and ausforming temperature on the martensite start temperature (Ms) \\ of a medium-carbon bainite steel was investigated by thermal simulation, optical microscope, scanning \\ electron microscope, etc. It is already known that small strain increases the $\mathrm{M}_{\mathrm{S}}$, while larger strain \\ decreases the Ms. However, the effect of ausforming temperature on the MS has not been reported and \\ clarified. In this study, the concepts of critical strain $\left(\varepsilon_{c}\right)$ and saturated strain $\left(\varepsilon_{s}\right)$ are proposed. The Ms at \\ the critical strain is equal to the $\mathrm{MS}_{\mathrm{S}}$ of the nondeformed specimen. The saturation strain, which is first \\ observed, is the strain value, and the Ms does not further decrease with the increasing strain. The results \\ show that the Ms depends on the strain amount of ausforming but is not affected by the ausforming \\ temperature. Moreover, with the increase of strain amount and ausforming temperature, the length of the \\ martensite laths decreases. In addition, the hardness of the specimen increases with the increase of the \\ ausforming strain amount, whereas the ausforming temperature has little effect on the hardness. \\ Disciplines \\ Engineering | Science and Technology Studies

\section{Publication Details} \\ Tian, J., Chen, G., Xu, Y., Jiang, Z. \& Xu, G. (2019). Comprehensive Analysis of the Effect of Ausforming on \\ the Martensite Start Temperature in a Fe-C-Mn-Si Medium-Carbon High-Strength Bainite Steel. \\ Metallurgical and Materials Transactions A: Physical Metallurgy and Materials Science, 50 (10), \\ 4541-4549.
}




\section{Comprehensive analysis of the effect of ausforming on martensite start} temperature in a Fe-C-Mn-Si medium-carbon high-strength bainite steel Junyu Tian ${ }^{a}$, Guanghui Chen ${ }^{a}$, Yaowen Xu ${ }^{a}{ }^{*}$, Zhengyi Jiang $^{b}$, Guang ${ }^{a}{ }^{a}{ }^{*}$

a) The State Key Laboratory of Refractories and Metallurgy, Wuhan University of Science and Technology, Wuhan 430081, China;

b) School of Mechanical, Materials, Mechatronic and Biomedical Engineering, University of Wollongong, Wollongong, NSW 2522 Australia.

Junyu Tian, E-mail: 13164178028@163.com; Guanghui Chen, E-mail: chenguanghui@wust.edu.cn; *Corresponding author: Yaowen Xu, E-mail: xuyw@wust.edu.cn; Zhengyi Jiang, E-mail: jiang@uow.edu.au; *Corresponding author: Guang Xu, E-mail: xuguang@wust.edu.cn.

Abstract: The comprehensive effect of strain and ausforming temperature on the martensite start temperature $\left(\mathrm{M}_{\mathrm{S}}\right)$ of a medium-carbon bainite steel was investigated by thermal simulation, optical microscope (OM), scanning electron microscope (SEM) etc. It is already known that small strain increases the $M_{S}$, while larger strain decreases $\mathrm{M}_{\mathrm{S}}$. But, the effect of ausforming temperature on $\mathrm{M}_{\mathrm{S}}$ has not been reported and clarified. In this study, the concepts of critical strain $\left(\varepsilon_{c}\right)$ and saturated strain $\left(\varepsilon_{s}\right)$ are proposed. The $M_{S}$ at the critical strain is equal to the $M_{S}$ of the non-deformed specimen. The saturation strain, which is first observed, is the strain value, and the $\mathrm{M}_{\mathrm{S}}$ at which does not further decrease with the increasing strain. The results show that the temperature of $\mathrm{M}_{\mathrm{S}}$ depends on the strain amount of ausforming, but is not affected by the ausforming temperature. Moreover, with the increase of strain amount and ausforming temperature, the length of the martensite laths decreases. In addition, the hardness of specimen increases with the increase of ausforming strain amount, whereas the ausforming temperature has little effect on the hardness.

Keywords : ausforming; martensite start temperature; critical strain; saturation strain; microstructure; hardness 


\section{Introduction}

The strength of steels is one of the main indexes in developing the new generation steels. Bainite steel with better mechanical properties is one of the advanced high strength steels [1-4]. Bhadeshia and Caballero proposed a novel nano-structured superbainite steel with an ultimate tensile strength of $2.5 \mathrm{GPa}$ [5-7]. A very low transformation temperature near the martensite start temperature $\left(\mathrm{M}_{\mathrm{S}}\right)$ is necessary to obtain the nano-structured bainite plates. In addition, ausforming is an indispensable step in the production of metals. It has been proved that ausforming affects the $\mathrm{M}_{\mathrm{S}}$. Therefore, the investigation on the effect of ausforming on the $\mathrm{M}_{\mathrm{S}}$ is significant for the control of the transformation and microstructure of the superbainite steel.

It is generally acknowledged that the deformation causes the mechanical stabilization of austenite, i.e. $\mathrm{M}_{\mathrm{S}}$ decreases after deformation [8-14]. For example, the effect of ausforming on martensite transformation and microstructure in a medium-carbon Si-Al-rich alloy was investigated by Zhang et al. [8,9]. They found that ausforming decreased the $M_{S}$ due to resisting of $\gamma-\alpha$ interface motion by dislocation debris. The similar results were reported in Refs. [10-14]. However, a different result was proposed by He et al. [15]. They studied the effect of ausforming amount on the $\mathrm{M}_{\mathrm{S}}$ in a $0.22 \mathrm{C}$ (wt.\%) low-carbon steel and claimed that a small deformation increases the $\mathrm{M}_{S}$, while a large deformation decreases the $\mathrm{M}_{\mathrm{S}}$ temperature. Summarizing the results of existing references, it is known that ausforming strain amount has various effects on the $\mathrm{M}_{S}$, so it is significant to further study the effects of ausforming strain amount on $\mathrm{M}_{\mathrm{S}}$. 

content on the $\mathrm{M}_{\mathrm{S}}$ have not been reported and clarified. Therefore, the studies on the

3 effect of ausforming temperature and carbon content on the $\mathrm{M}_{\mathrm{S}}$ are necessary. In the

4 present study, three different ausforming temperatures with different strain amounts

5 were designed to investigate the effects of the ausforming temperature, strain amount

6 and carbon content on the temperature of $\mathrm{M}_{\mathrm{S}}$. The work is meaningful for the control

7 of the transformation, microstructure and mechanical properties in nano-structured

8 bainite steels.

9

\section{Materials and methods}

The experimental steel is a Fe-0.40C-2.21Mn-1.54Si-0.22Mo (wt.\%) high-strength bainite steel. The steel was refined and cast in the form of $50 \mathrm{~kg}$ ingot using a laboratory-scale vacuum furnace, followed by hot-rolling and air-cooling to room temperature. And then the experimental steel was tempered at $700{ }^{\circ} \mathrm{C}$ for $24 \mathrm{~h}$ to minimize interior stress and facilitate machining. The specimens for the thermal simulation experiments were machined to cylinders of $6 \mathrm{~mm}$ diameter and $15 \mathrm{~mm}$ height. The thermal simulation experiments were conducted on a Gleeble-3500 simulator. The specimens were heated to $900{ }^{\circ} \mathrm{C}$ at $10{ }^{\circ} \mathrm{C} \mathrm{s}^{-1}$ and isothermally held for 5 min for austenitization. And then, the austenization specimens were respectively quenched to 860,600 and $300{ }^{\circ} \mathrm{C}$ at a high cooling rate. The cooling rate was fast enough to avoid the high temperature transformation. Subsequently, the specimens were compressed to strains of $5 \%, 8 \%, 15 \%, 30 \%$ and $50 \%$ at a strain rate of $10 \mathrm{~s}^{-1}$, respectively. Finally, all deformed specimens were quenched to ambient temperature. 
1 The specific experimental procedures were shown in Fig. 1. Besides, a specimen

2 without deformation was directly quenched to ambient temperature after austenization

3 at $900{ }^{\circ} \mathrm{C}$ to measure the $\mathrm{M}_{\mathrm{S}}$ of non-deformed specimen. After thermal simulation

4 experiments, all specimens were mechanically polished and etched with $4 \%$ nital. The

5 microstructure was observed using a Zeiss optical microscope (OM) and a Nova 400

6 Nano scanning electron microscope (SEM). The hardness was measured using a

$7 \quad$ Vickers hardness tester.

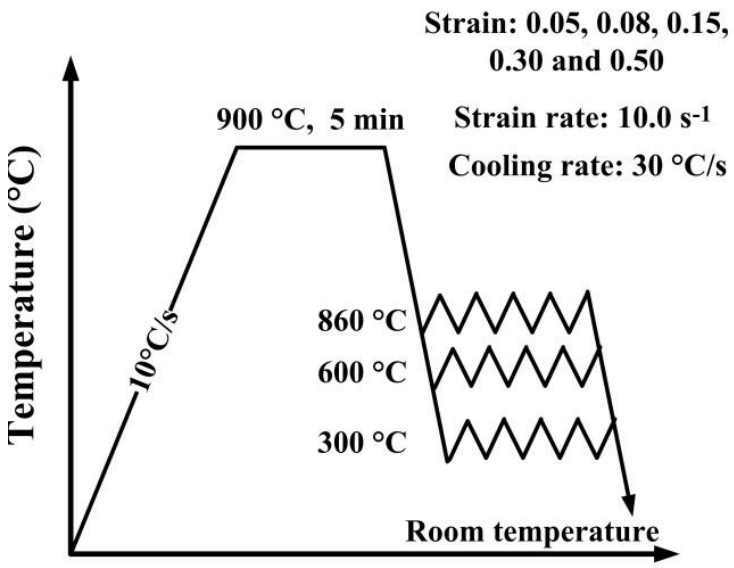

Time (s)

Fig. 1 Experimental procedure

\section{Results and discussion}

\subsection{Analysis on the dilation}

Figure 2 a presents an example $\left(5 \%\right.$ strain deformation at $\left.600{ }^{\circ} \mathrm{C}\right)$ to illustrate the diameter change of specimen with temperature during the whole thermal simulation process. The specimen was heated from ambient temperature to $900{ }^{\circ} \mathrm{C}$ for austenization, resulting in the dilatation increasing (from point $\mathrm{A}$ to $\mathrm{B}$ ). Then, the specimen was cooled to $600{ }^{\circ} \mathrm{C}$, resulting in the decrease in dilatation continuously (from point $\mathrm{B}$ to $\mathrm{C}$ ). After that, the specimen was compressed to $5 \%$ strain at $600{ }^{\circ} \mathrm{C}$, 
1 causing the vertical increase in dilatation (from point $\mathrm{C}$ to $\mathrm{D}$ ). At last, the deformed

2 specimen was cooled to ambient temperature and the dilatation decreased first and

3 then increased. The inflection point represented the beginning of martensite

4 transformation and corresponding temperature $\left(\mathrm{M}_{\mathrm{S}}\right)$ was measured according to the

$5 \quad$ tangent method [16].

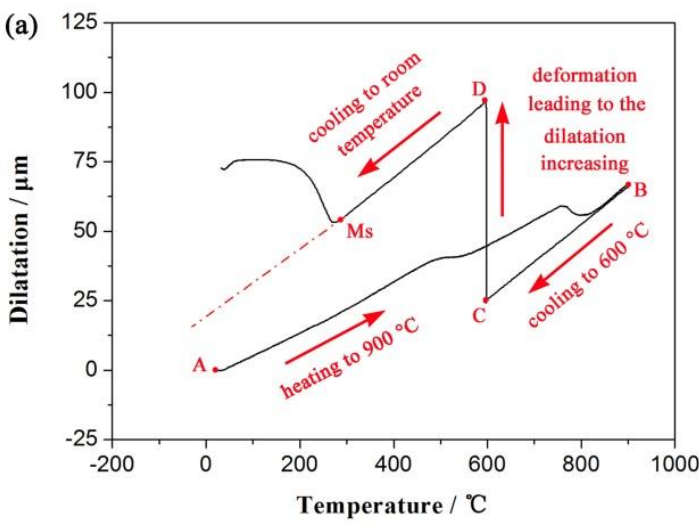

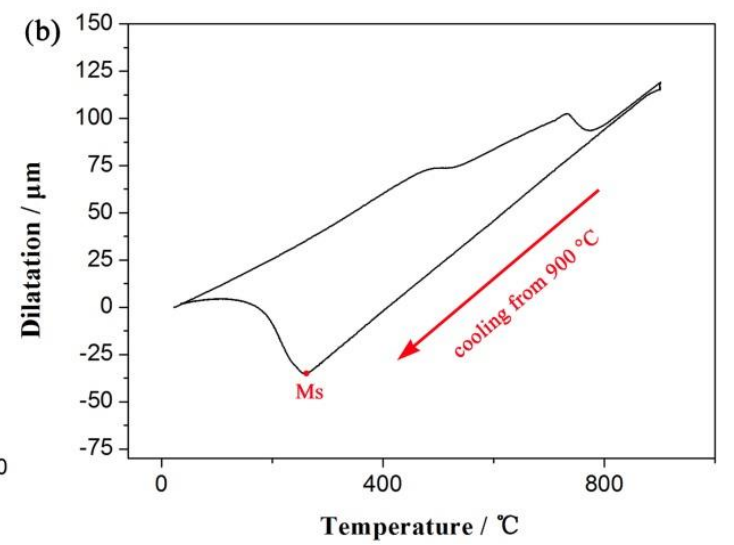

Fig. 2 Example of dilatation change with temperature during the whole process: (a) $600{ }^{\circ} \mathrm{C}+0.05$ strain specimen; and (b) non-deformation specimen As is widely known, high temperature diffusive transformation such as ferrite and bainite transformation is companied with the rejection of carbon atoms into surrounding untransformed austenite, resulting in the increase of the chemical stability of untransformed austenite [17-19], and thereby decreases the $\mathrm{M}_{\mathrm{S}}$. In addition, ausforming also affects ferrite and bainite transformation by providing heterogeneous nucleation [20-22], which may shorten the incubation time of transformation. Moreover, transformation may happen during deformation as well. To eliminate the influence caused by ferrite and bainite transformation on $\mathrm{M}_{\mathrm{S}}$, the cooling rate should be high enough to avoid ferrite and bainite transformation. Figure $2 b$ shows the temperature-dilatation curves of specimen without deformation. The dilatation went 
1 down straightly, indicating that no transformation happened before $\mathrm{M}_{\mathrm{S}}$. The dilatation

2 for deformed specimen (Fig. 2a) also went down straightly after deformation.

3 Therefore, the cooling rate in the present study was high enough to avoid high

4 temperature transformation.

5 For the deformation process, the deformation time can be calculated using 6 following Equation (1):

$$
-\ln \left(L / L_{0}\right)=\dot{\varepsilon} \cdot t
$$

8 where $L$ and $L_{0}$ is the height of specimen after and before deformation, respectively.

9 The $\dot{\varepsilon}$ is the strain rate $\left(\dot{\varepsilon}=10 \mathrm{~s}^{-1}\right)$, and $t$ is the consuming time for deformation. The calculated time is $0.068 \mathrm{~s}$ for 0.05 strain. According to author's previous study [23], there was no transformation during deformation. In addition, it has been proved that stress influences the $\mathrm{M}_{\mathrm{S}}$ as well $[24,25]$. The applied stress on the specimen for deformation was immediately unloaded after deformation. Figure 3 shows the stress during the whole simulation experiment for specimen with $15 \%$ strain at $300{ }^{\circ} \mathrm{C}$, illustrating that there was little stress during the cooling process after deformation. This means that the $\mathrm{M}_{\mathrm{S}}$ was not affected by stress. Hence, it can be concluded that the changes of $\mathrm{M}_{\mathrm{S}}$ in the present study were only

18 affected by ausforming, rather than other factors such as transformation and stress 19 before or during martensite transformation. 


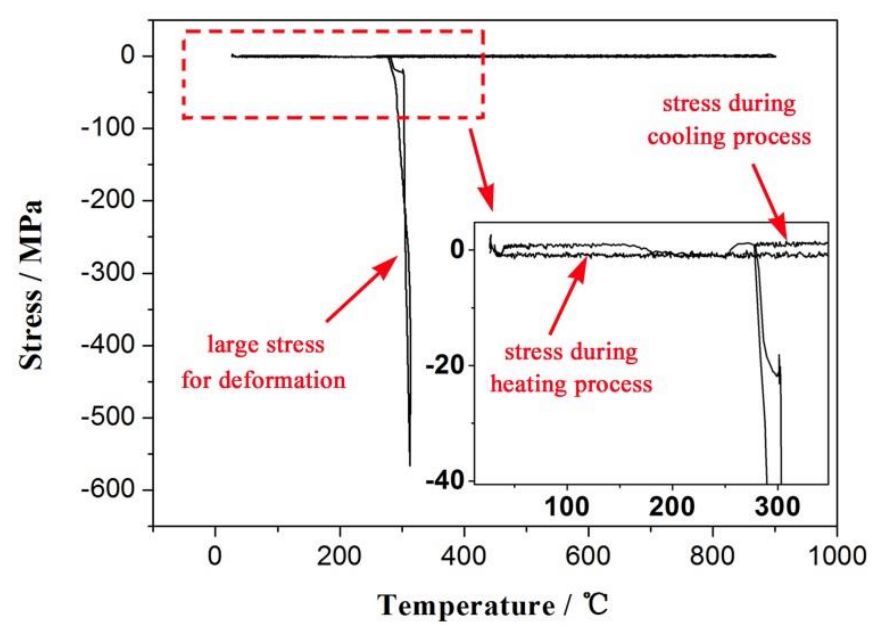

2 Fig. 3 The change of stress during the whole simulation test for specimen with 0.15

3 strain at $300{ }^{\circ} \mathrm{C}$, illustrating the little influence of stress on $\mathrm{M}_{\mathrm{S}}$ during cooling process

\section{$4 \quad 3.2$ Critical strain and saturation strain}

The $\mathrm{M}_{\mathrm{S}}$ were determined based on the temperature-dilatation curves. Figure 4

6 presents the curve of temperature and dilatation during cooling process of specimens

7 without deformation and deformed to 0.05 strain at 300,600 and $860{ }^{\circ} \mathrm{C}$, respectively.

8 During the cooling process, the undercooled austenite started to transform into

9 martensite when the temperature reached $\mathrm{M}_{\mathrm{S}}$, resulting in obviously increase in 10 dilatation. The $\mathrm{M}_{\mathrm{S}}$ for specimen without deformation was $269{ }^{\circ} \mathrm{C}$ and $\mathrm{M}_{\mathrm{S}}$ for

11 specimens with 0.05 strain at different ausforming temperatures were 284, 282 and $12284^{\circ} \mathrm{C}$, respectively. Thus, compared with non-deformation, the ausforming with 0.05 13 strain at different temperatures caused the increase of $\mathrm{M}_{\mathrm{S}}$. 

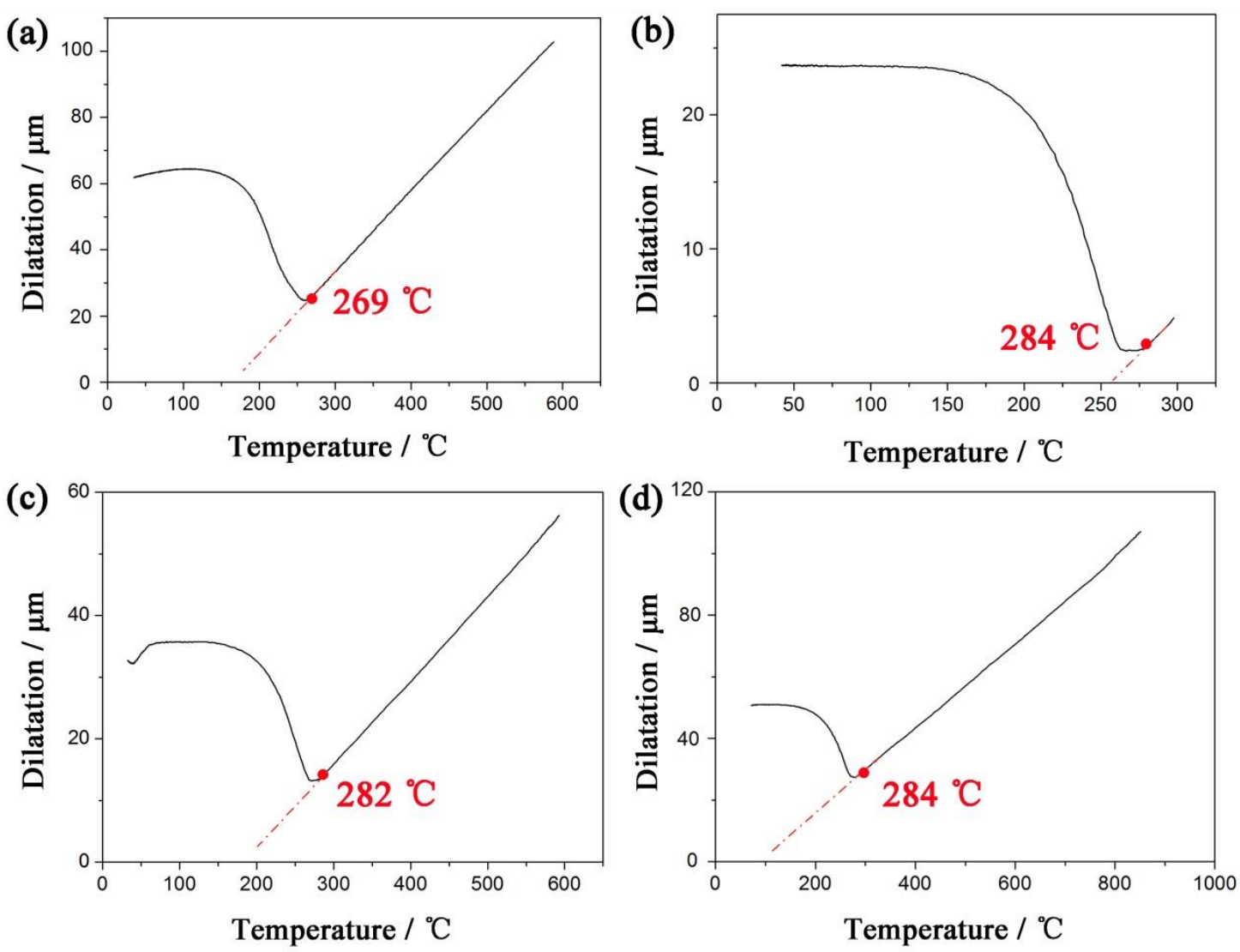

Fig. 4 Temperature-dilatation curves illustrating the $\mathrm{M}_{\mathrm{S}}$ of different specimens: (a) without deformation; (b) $300{ }^{\circ} \mathrm{C}+0.05$ strain; (c) $600{ }^{\circ} \mathrm{C}+0.05$ strain; and (d) $860{ }^{\circ} \mathrm{C}+0.05$ strain

The $\mathrm{M}_{\mathrm{S}}$ for other deformed specimens were obtained using the same method and given in Fig. 5. It is clear that compared with the specimen without deformation, the

$7 \quad M_{S}$ of deformed specimens first increased with strain, and then reached the peak value 8 at the strain of 0.05 . As the strain further increased, the $\mathrm{M}_{\mathrm{S}}$ decreased. There was a

9 critical strain $\left(\varepsilon_{c}\right)$ between 0.05 and 0.15 strain, which was the inflection point of the effect of ausforming on the $\mathrm{M}_{\mathrm{S}}$. Compared with the $\mathrm{M}_{\mathrm{S}}$ of non-deformed specimen, the ausforming increases the $\mathrm{M}_{\mathrm{S}}$ temperature before reaching to $\varepsilon_{c}$, while it decreases

12 the $\mathrm{M}_{\mathrm{S}}$ after $\varepsilon_{c}$. In addition, the $\mathrm{M}_{\mathrm{S}}$ reached a stable value at strain of 0.15 , indicating that the increase of strain amount after 0.15 strain had no significant influence on the 
$1 \quad \mathrm{M}_{\mathrm{S}}$. The strain amount corresponding to the stable $\mathrm{M}_{\mathrm{S}}$ is termed as saturation strain $2\left(\varepsilon_{S}\right)$.

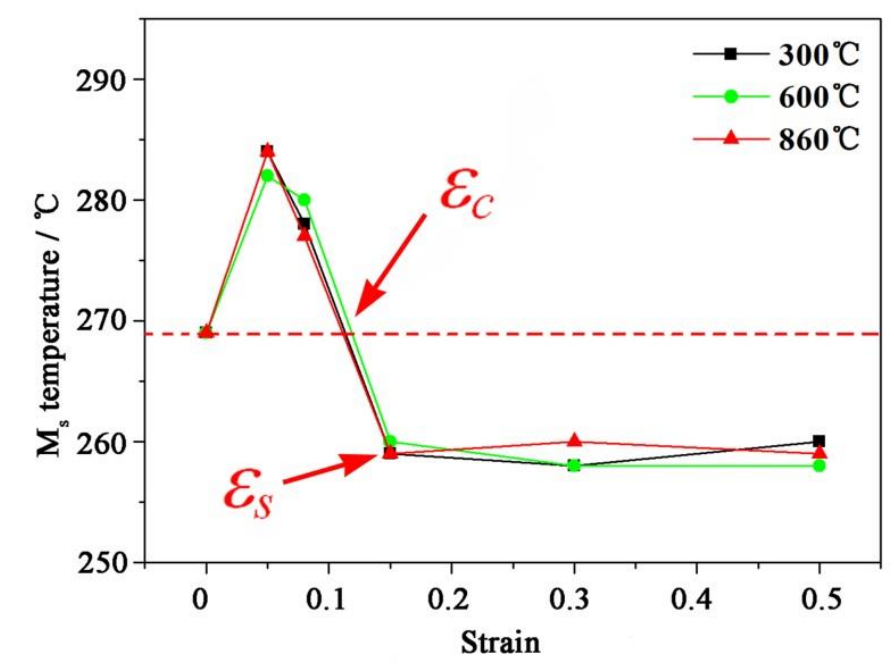

3

Fig. 5 The change of $M_{S}$ with strain amount and ausforming temperature

Figure 5 illustrates the effects of strain amount and ausforming temperature on the $\mathrm{M}_{\mathrm{S}}$, indicating that the $\mathrm{M}_{\mathrm{S}}$ did not change with ausforming temperature but was distinctly affected by the deformation amount. The $\mathrm{M}_{\mathrm{S}}$ firstly increased with the increasing strain, and then reached the peak value when the strain amount was 0.05. As the strain amount increased sequentially to 0.15 , the $\mathrm{M}_{\mathrm{S}}$ decreased sharply and was apparently smaller than the $\mathrm{M}_{\mathrm{S}}$ of specimen without deformation. The further increase in deformation amount after 0.15 strain had no significant effect on the $\mathrm{M}_{\mathrm{S}}$, i.e. the $\mathrm{M}_{\mathrm{S}}$ tended to be constant. No matter at which temperature the specimen was deformed, the $\mathrm{M}_{\mathrm{S}}$ of specimen deformed for 0.05 strain was higher than that of non-deformed specimen. The $\mathrm{M}_{\mathrm{S}}$ of specimen with 0.15 strain was lower than that of non-deformed specimen. This manifests that there must be a critical deformation amount $\varepsilon_{c}$ (shown in Fig. 5). The $\mathrm{M}_{\mathrm{S}}$ increased by a small strain less than $\varepsilon_{c}$ and decreased at a strain larger than $\varepsilon_{c}$. 

formula (2) [26]:

$$
M s=M s^{s}-k d^{-1 / 2}
$$

4 where the $M s$ is the martensite start temperature of polycrystalline material, and the

$5 M s^{s}$ is the martensite start temperature of single crystal material, of which the diameter is regarded as infinity. The $k$ is constant and the $d$ is diameter of parent phase

7 grain (undercooled austenite). Therefore, the function of $\mathrm{M}_{\mathrm{S}}$ and $d^{-1 / 2}$ is linear as

8 shown in Fig. 6, indicating that the $\mathrm{M}_{\mathrm{S}}$ should increase with the diameter of the parent

9 phase grain. Figures $7 \mathrm{a}-\mathrm{c}$ displays the micrographs of prior austenite grains (PAG) and prior austenite grain boundaries (PAGB) of samples with different strains at $860{ }^{\circ} \mathrm{C}$. The values of PAG were calculated by Image-Pro Plus software based on the diagonal method. Two diagonals are drawn randomly in each grain. The average value of the two diagonals is calculated as the size of this grain. Finally, the average value of the sizes of all grains is selected as the grain size of the whole micrograph. In order to achieve the higher accuracy, at least the results of three micrographs are reported is obvious that the size of deformed austenite grains decreases with increasing strain. In this study, however, the $\mathrm{M}_{\mathrm{S}}$ increased with the strain when the deformation amount was small. Then, the $\mathrm{M}_{\mathrm{S}}$ decreased and tended to be constant as the strain increased 
1 further. Hence, the $\mathrm{M}_{\mathrm{S}}$ not only depended on the size of austensite grains, but also was

2 affected by ausforming. In addition, the length of martensite laths is related to prior

3 austenite grain size. The smaller austensite grain size results in shorter length of

4 martensite laths. Hence, when the strain is large, the length of martensite laths is

5 shorter (Fig. 11) due to smaller austenite grains. Although the length of martensite

6 laths decreases with the increase of strain, the $\mathrm{M}_{\mathrm{S}}$ temperature is not changed with the

7 same trend, indicating that the length of martensite laths depends on not only the $\mathrm{M}_{\mathrm{S}}$

8 temperature, but also, more importantly, strain amount.

9

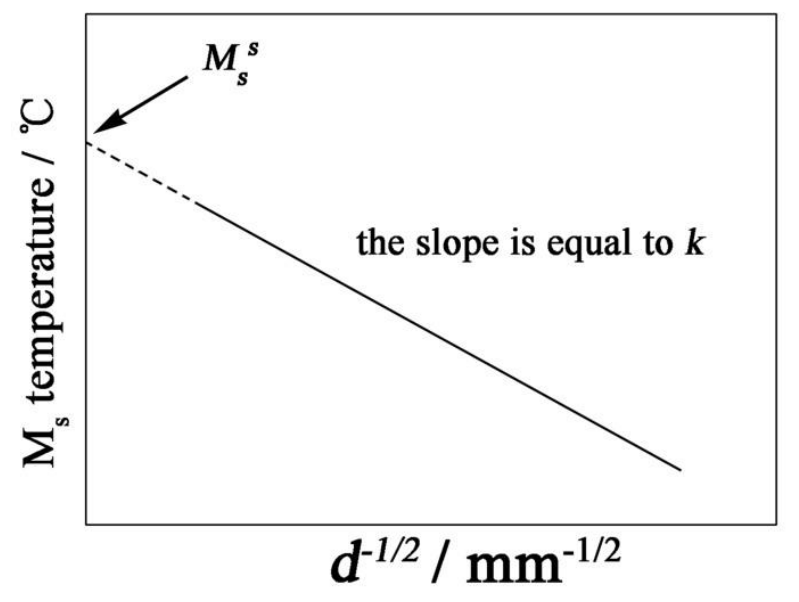

Fig. 6 The relationship between $M_{S}$ and $d^{-1 / 2}$ according to Hall-Petch formula

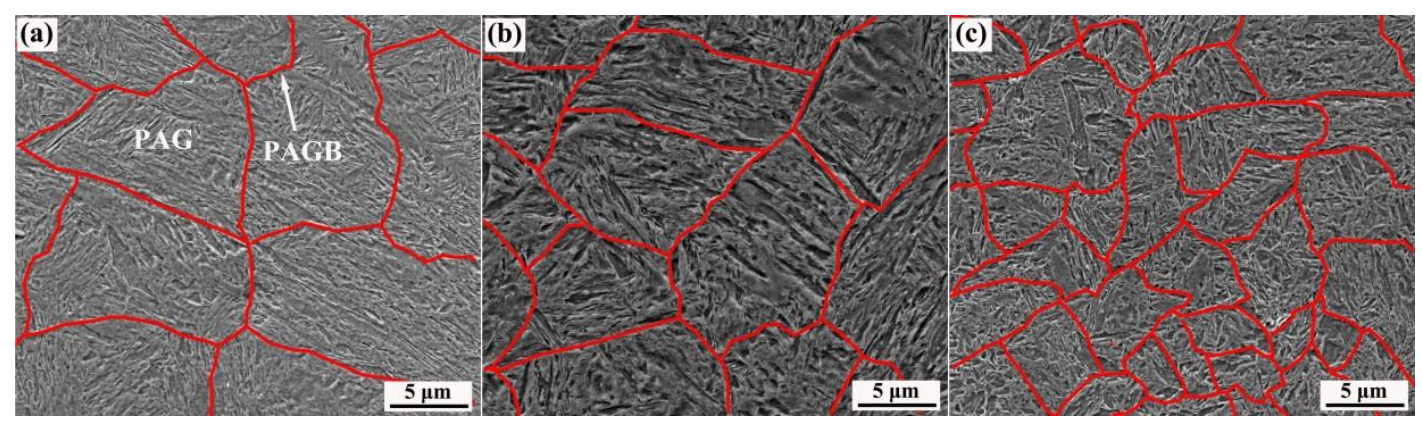

Fig. 7 Examples of PAG for samples deformed at $860{ }^{\circ} \mathrm{C}$ with different strains: (a)

$$
0.05 \text {; (b) } 0.15 \text {; and (c) } 0.50
$$


Table 1 The measured PAG of different deformed samples

\begin{tabular}{cccc}
\hline \multirow{2}{*}{$\begin{array}{c}\text { Deformation } \\
\text { temperature }\end{array}$} & \multicolumn{3}{c}{ Strain amount } \\
\cline { 2 - 4 } & $\mathbf{0 . 0 5}$ & $\mathbf{0 . 1 5}$ & $\mathbf{0 . 5 0}$ \\
\hline $300{ }^{\circ} \mathbf{C}$ & $24.2 \pm 3.1$ & $17.6 \pm 2.5$ & $11.6 \pm 1.4$ \\
$600{ }^{\circ} \mathbf{C}$ & $18.4 \pm 1.8$ & $13.1 \pm 1.4$ & $9.5 \pm 1.7$ \\
$860^{\circ} \mathbf{C}$ & $13.4 \pm 2.3$ & $10.3 \pm 1.7$ & $6.2 \pm 1.5$ \\
\hline
\end{tabular}

The displacive mechanism of martensitic transformation is generally accepted [27-29]. The formation of martensite consists of nucleation and growth. In a deformed austenite grain, the deformation leads to the formation of geometrically necessary dislocations (GNDs) at the austensite grain boundaries and randomly distributed dislocations within the austensite grains [30,31]. As the strain increases, the average of the density of GNDs increases linearly and the GNDs accumulate near the austenite grain boundaries. For the specimens with small strain, martensite transformation preferentially nucleates at the dislocations accumulated at the austenite grain boundaries before the formation of martensite. Once the primary martensite nucleates at the dislocations, the defect generated in the $\alpha-\gamma$ interfaces may immediately trigger further martensitic transformation in an autocatalytic chain-like manner. The small strain offers the preferential nucleation sites for martensitic transformation compared with the specimen without deformation. As a result, the $\mathrm{M}_{\mathrm{S}}$ increases with strain smaller than the critical strain. The similar results were reported in Refs. [32-34].

With the further increasing strain (Fig. 5), however, the $\mathrm{M}_{\mathrm{S}}$ decreased and then tended to be constant. When the strain was 0.08 , the $\mathrm{M}_{\mathrm{S}}$ was lower than that at 0.05 strain but still higher than that of non-deformed specimen. Besides, as the strain increased to the critical deformation amount $\varepsilon_{c}$, the $\mathrm{M}_{\mathrm{S}}$ further decreased to be equal the $\mathrm{M}_{\mathrm{S}}$ of non-deformed specimen. When the strain was larger than $\varepsilon_{c}$, the $\mathrm{M}_{\mathrm{S}}$ of 
deformed specimen was lower than that of non-deformed specimen and decreased with the increasing strain until saturation strain $\left(\varepsilon_{s}\right)$. Regarding to the deformed specimens, the competitive relationship between nucleation and growth affects the martensitic transformation and $\mathrm{M}_{\mathrm{S}}$. As the strain increases, the increasing amount of dislocations remains inside the deformed austenite grains and leads to a high density of dislocations, both which restricts the growth of martensite laths. Furthermore, the appearance of subgrains induced by large strain also retards the growth of martensite laths. Therefore, the martensite transformation was delayed and the $\mathrm{M}_{\mathrm{S}}$ decreased.

When the strain increased from 0.15 to 0.50 , the $\mathrm{M}_{\mathrm{S}}$ tended to be constant. The restricting effect of deformation on the $\mathrm{M}_{\mathrm{S}}$ was saturated when the strain was 0.15 . In Kundu's research [31], the dislocations introduced by large strain also accumulate at the boundaries of subgrains, thus providing nucleation sites for martensitic transformation at a later stage. The martensite laths forming at the boundaries of subgrains rapidly grow and stop at the other side of the subgrain boundaries. The dislocations accumulated at the subgrain boundaries are saturated when the strain is large enough [15]. Hence, the extent to which the saturated dislocations promote nucleation does not change with increasing strain, resulting in basically stable $\mathrm{M}_{\mathrm{S}}$.

In previous study, the effect of ausforming strain amount on the $M_{S}$ in a low-carbon bainite steel was studied by He et al. [15]. They claimed that the small strain increases the $\mathrm{M}_{\mathrm{S}}$ while large strain decreases the $\mathrm{M}_{\mathrm{S}}$. The similar result was obtained in a medium-carbon bainite steel in the present research. However, in their study, the critical strain amount $\varepsilon_{c}$ was about 0.23 for a low-carbon steel, while it was 
1 about 0.10 for a medium-carbon steel in this study. This means that the critical strain

2 depends on the chemical composition of steel, especially carbon content. Moreover,

3 the saturated strain $\varepsilon_{s}$ was not observed and defined in previous study, whereas it was

4 firstly observed and defined in the present study. Compared with low-carbon steels,

5 medium-carbon steels contain more carbon and other alloying element such as

6 manganese $(\mathrm{Mn})$ and silicon $(\mathrm{Si})$, resulting in more elastic distortion. On the other

7 hand, the solute atoms segregated on the dislocations have the pinning effect on the

8 dislocations. Thus, more serious work hardening happens in medium-carbon steels,

9 causing the decrease of $\varepsilon_{c}$. In addition, summarizing the experimental results of the

10 two kinds of steels, it can be inferred that although the appeared in medium-carbon

11 steel but not in low-carbon steels, the $\varepsilon_{S}$ may still appear in low-carbon steel when a

12 certain very large strain was loaded.

13 The regression equation reflecting the influence of strain amount on $\mathrm{M}_{\mathrm{S}}$ is given

14 as following Equation (3) using the software of Origin 8.0:

$$
M_{S}=269.4511+361.3568 \varepsilon-2929.44 \varepsilon^{2}
$$

where the $\varepsilon$ is the strain amount, indicating that the $\mathrm{M}_{\mathrm{S}}$ follows the parabola law before the $\varepsilon_{s}$. Figure 8 presents the measured value and the corresponding simulated curve $(\varepsilon<0.15)$. The correlation coefficient is 0.94609 , meaning that the Equation (3)

19 is of good precision. 


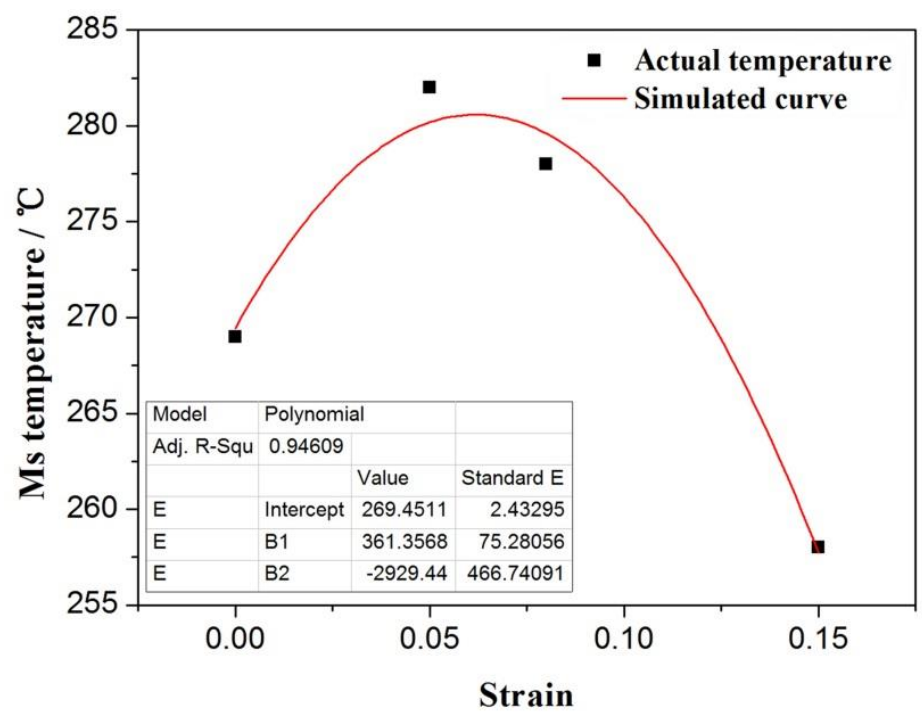

2 Fig. $8 \mathrm{M}_{\mathrm{S}}$ change following the parabola law at the strain before reaching the $\varepsilon_{s}$

$3 \quad 3.3$ Effect of ausforming temperature on $M_{S}$

It is observed in Fig. 5 that different ausforming temperatures (300, 600 and $860{ }^{\circ} \mathrm{C}$ ) had no significant effect on $\mathrm{M}_{\mathrm{S}}$, critical strain $\varepsilon_{c}$ and saturated strain $\varepsilon_{s}$. The stress-strain curves during the compression deformation process at different ausforming temperatures are presented in Fig. 9. It indicates that no dynamic recrystallization occurred for all deformation conditions. Obvious dynamic recovery happened at 600 and $860{ }^{\circ} \mathrm{C}$, while little dynamic recovery occurred at $300{ }^{\circ} \mathrm{C}$. Theoretically, the density of the dislocations near austenite grain boundaries in the specimens deformed at $300{ }^{\circ} \mathrm{C}$ should be higher than that in other two specimens with deformation at 600 and $860{ }^{\circ} \mathrm{C}$. It should have led to the different $\mathrm{M}_{\mathrm{S}}$ in different specimens at different ausforming temperatures. However, according to the results in Fig. 5 the ausforming temperature has little effect on $\mathrm{M}_{\mathrm{S}}$. It implied that the influence of austenite grain size cannot be ignored. 


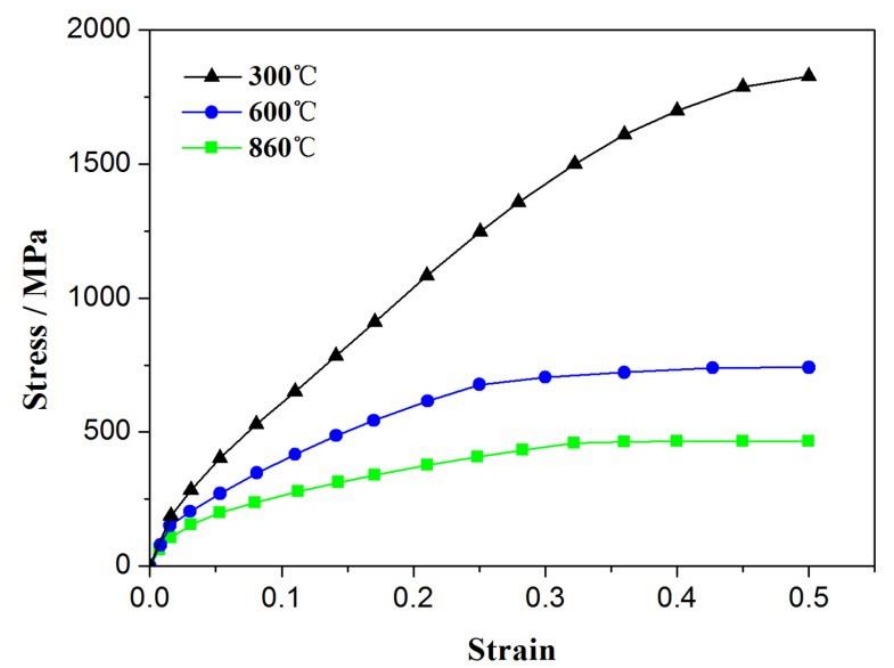
8 smaller density of dislocations, leading to the decrease of $\mathrm{M}_{\mathrm{S}}$. But smaller grain size

9 at high ausforming temperature provided more nucleation sites for martensite transformation. It is the combination of the dislocation density and austenite grain size that affects the $\mathrm{M}_{\mathrm{S}}$, contributing to the little influence of ausforming temperature on

Fig. 9 Stress-strain curves of the specimens deformed at 300, 600 and $860{ }^{\circ} \mathrm{C}$, indicating no dynamic recrystallization happened

The OM microstructures at different deformation conditions are shown in Fig. 10. It illustrates that the size of austenite grains at $860{ }^{\circ} \mathrm{C}$ (Figs. 10e and 10f) was apparently smaller than that at $300{ }^{\circ} \mathrm{C}$ (Figs. 10a and 10b). For the specimens deformed at different temperatures, the higher ausforming temperature caused the $\mathrm{M}_{\mathrm{S}}$. It is a main novelty in this study. 


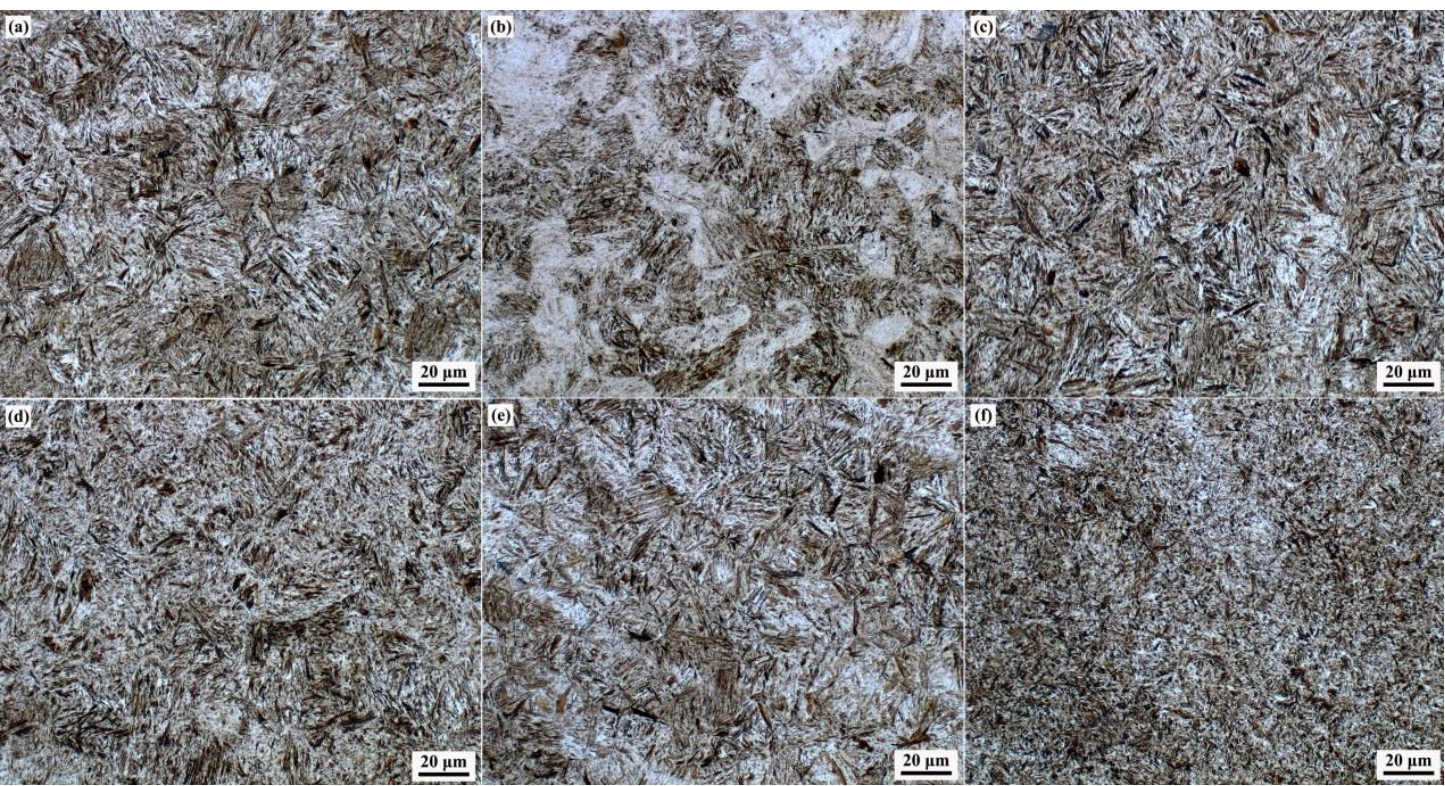

Fig. 10 The OM microstructure of different specimens: (a) $300{ }^{\circ} \mathrm{C}+0.05$ strain; (b)

$300{ }^{\circ} \mathrm{C}+0.50$ strain; (c) $600{ }^{\circ} \mathrm{C}+0.05$ strain; (d) $600{ }^{\circ} \mathrm{C}+0.50$ strain; (e) $860{ }^{\circ} \mathrm{C}+0.05$

$$
\text { strain; and (f) } 860{ }^{\circ} \mathrm{C}+0.50 \text { strain }
$$

\subsection{Microstructure}

The microstructure illustrates that the size of the austenite grains decreased with the increasing ausforming temperature (Fig. 10). The austenite grains tended to be broken by the deformation at a high temperature. For the specimens deformed at $860{ }^{\circ} \mathrm{C}$, the austenite grains were the finest at the same strain amount, leading to the shortest martensite laths. The micrographs with a higher magnification of 10000x of the specimens treated by different ausforming conditions are presented in Fig. 11, indicating that the growth of martensite laths in original austenite is hindered by subgrain boundary (Fig. 11c). And the similar phenomenon was also observed in Ref. [15]. In addition, martensite laths grow from the prior austenite grain boundary (PAGB), as marked with arrow in Figs. 11a-e. It is difficult to observe the martensite laths on PAGB in Fig. 11f due to the finest microstructure. In addition, it also can be 
1 observed that the martensite laths of non-deformed specimen (Fig. 11a) were longer

2 than those of deformed specimens. It can be observed that the length of martensite

3 laths decreased with the increasing strain (Figs. 11b-d and Figs. 11e-g). The growth of

4 martensite laths was limited in austenite grains. When the strain amount was small

$5 \quad(\varepsilon=0.05)$, the prior austenite grains were larger, resulting in the longer martensite laths.

6 The prior austenite grains became smaller with the increase of strain, leading to the

7 shorter martensite laths (Figs. 11d and 11g). This is attributed to the growth

8 retardation of martensite by subgrain boundaries. For specimens with the largest strain

9 of 0.50 , the parent austensite grains were obviously broken, resulting in the shortest

10 martensite laths. Moreover, compared with the specimens deformed at $300{ }^{\circ} \mathrm{C}$, the

11 size of martensite laths at $860{ }^{\circ} \mathrm{C}$ was shorter. This is because austenite grains are

12 easily broken at high ausforming temperature. 


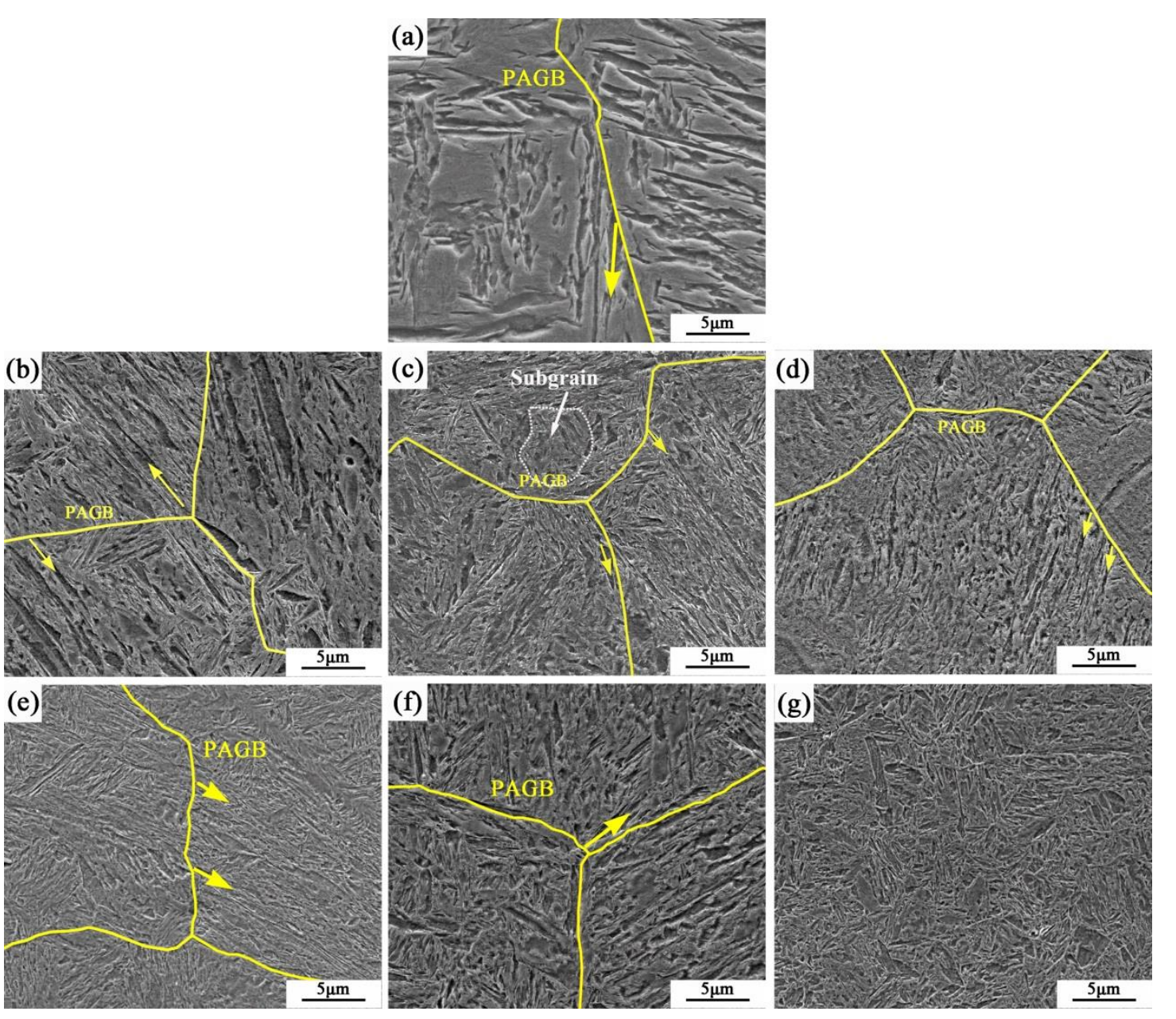

2 Fig. 11 The SEM microstructure of specimens treated by different processes: (a)

3 without deformation; (b) $300{ }^{\circ} \mathrm{C}+0.05$ strain; (c) $300{ }^{\circ} \mathrm{C}+0.15$ strain; (d) $300{ }^{\circ} \mathrm{C}+0.50$

$4 \quad$ strain; (e) $860{ }^{\circ} \mathrm{C}+0.05$ strain; (f) $860{ }^{\circ} \mathrm{C}+0.15$ strain; and (g) $860{ }^{\circ} \mathrm{C}+0.50$ strain

$5 \quad 3.5$ Effect of ausforming on the hardness

The hardnesses of different specimens were given in Fig. 12. It indicates that the

7 work hardening caused the increase of hardness with strain amount, while the

8 ausforming temperature had little effect on the hardness. When the ausforming

9 temperature was same, the increasing strain led to the decrease in the austensite grain

size and the increase in the dislocation density, contributing to the increase of harness

11 with strain. The change in hardness is related to the morphology of martensite laths.

12 Smaller austenite grain hinders the growth of martensite laths. Hence, when the strain 
1 amount is large, the martensite laths are refined (Fig. 11), resulting in a larger

2 hardness of the microstructure. Therefore, the hardness increased with strain. It is

3 noted that the ausforming temperature had no significant effect on the hardness,

4 which was consistent with the effect of ausforming temperature on the $\mathrm{M}_{\mathrm{S}}$. Therefore,

5 the hardness was mainly affected by the austensite grain size and the dislocation

6 density in this study, while the $\mathrm{M}_{\mathrm{S}}$ had no obvious influence on it.

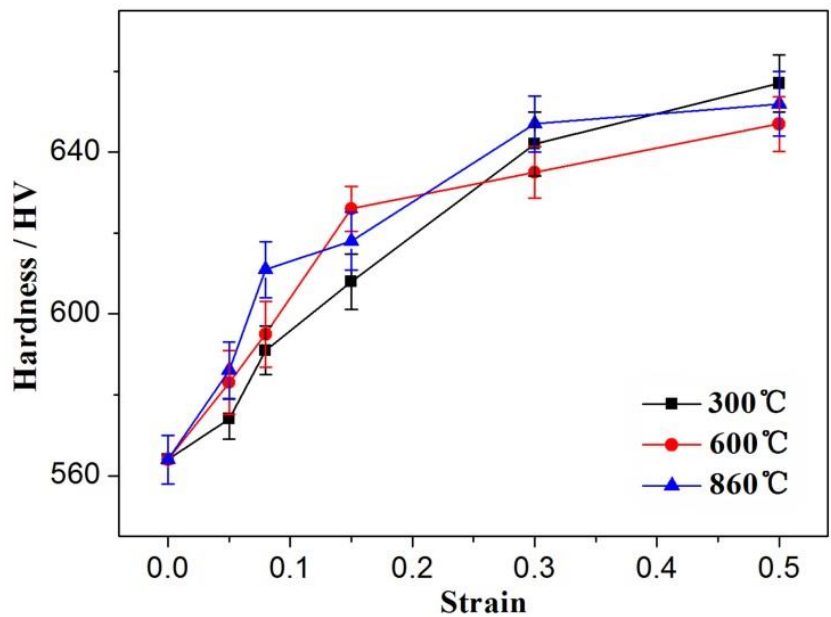

Fig. 12 The Vicker's hardness of specimens

In the present study, the effect of ausforming deformation on $\mathrm{M}_{\mathrm{S}}$ mainly focuses on the compressive strain. The purpose of the present research is to provide theoretical reference for industrial production. The deformation on austenite in industrial production is normally compressive deformation. Therefore, tensile deformation and hydrostatic stress was not studied here. The effect of tensile deformation and hydrostatic stress on $\mathrm{M}_{\mathrm{S}}$ should be conducted in the future study.

\section{Conclusions}

The effects of ausforming on the $\mathrm{M}_{\mathrm{S}}$ in a Fe-C-Mn-Si medium-carbon bainite steel were investigated. The following conclusions can be drawn: 
(1) The saturation strain $\varepsilon_{s}$ is firstly observed and defined. The $\mathrm{M}_{\mathrm{S}}$ tends to be

constant when the strain is larger than $\varepsilon_{s}$. Moreover, the critical strain $\varepsilon_{c}$ is proposed.

The strain smaller than $\varepsilon_{c}$ increases the $\mathrm{M}_{\mathrm{S}}$, whereas the $\mathrm{M}_{\mathrm{S}}$ decreases at the strain larger than $\varepsilon_{c}$.

(2) The ausforming temperature does not affect the $\mathrm{M}_{\mathrm{S}}$. The critical strain $\varepsilon_{c}$ and saturation strain $\varepsilon_{s}$ are not affected by the ausforming temperature.

(3) The length of martensite laths decreases with the increase of ausforming temperature and strain amount.

(4) The hardness of specimens increases with strain amount, while it is not affected by the ausforming temperature.

\section{Acknowledgements}

The authors gratefully acknowledge the financial supports from the National Natural Science Foundation of China (Nos.51874216 and 51704217), the Major Projects of Technology Innovation of Hubei Province (No.2017AAA116), the Science and Technology Project of Wuhan (2018010402011187), Hebei Joint Research Fund for Iron and Steel (E2018318013), Youth Foundation of Wuhan University of Science and Technology (2015XZ002), the State Key Laboratory Science Foundation for Youths (2016QN10) and the State Scholarship Fund of China Scholarship Council.

\section{References}

[1] H.J. Hu, G. Xu, L. Wang, Z.L. Xue, Y.L. Zhang and G.H. Liu: Mater. Des. 2015, vol. 84, pp.95-99.

[2] Y.X. Zhou, X.T. Song, J.W. Liang, Y.F. Shen and R.D.K. Misra: Mater. Sci. Eng. A 
2018, vol. 718, pp. 267-76.

[3] J. Zhao, K. Guo, Y.M. He, Y.F. Wnag and T.S. Wang: Scripta Mater. 2018, vol. 152, pp. 20-23.

[4] G.H. Chen, G. Xu, H.S. Zurob, H.J. Hu and X.L. Wan: Metall. Mater. Trans. A 2019, vol. 50, pp. 573-80.

[5] C. García-mateo, F.G. Caballero and H.K.D.H. Bhadeshia: Mater. Sci. Forum 2015, vol. 112, pp. 285-88.

[6] F.G. Caballero, C. García-mateo and M.K. Miller: JOM 2014, vol. 66, pp. 747-55.

[7] F.G. Caballero, C. García-mateo, C. Capdevila and C. García de Andrés: Mater. Manuf. Process. 2007, vol. 22, pp. 502-06.

[8] M. Maalekian, E. Kozeschnik, S. Chatterjee and H.K.D.H. Bhadeshia: Met. Sci. J. 2007, vol. 23, pp. 610-12.

[9] S. Chatterjee, H.S. Wang, J.R. Yang and H.K.D.H. Bhadeshia: Met. Sci. Technol. 2006, vol. 22, 641-44.

[10] J.R. Strife, M.J. Carr and G.S. Ansell: Metall. Trans. A 1976, vol. 8, 1471-84.

[11] M. Zhang, Y.H. Wang, C.L. Zheng, F.Z. Zhang and T.S. Wang: Mater. Des. 2014, vol. 62, pp. 168-74.

[12] M. Zhang, Y.H. Wang, C.L. Zheng, F.Z. Zhang and T.S. Wang: Mater. Sci. Eng. A 2014, vol. 596, 9-14.

[13] T. Sadasue, S. Suzuki, M. Suwa, S. Mitao and K. Takahashi: Mater. Sci. Forum 2003, vol. 426, 1493-98.

[14] T.S. Wang, M. Zhang, Y.H. Wang, J. Yang and F.C. Zhang: Scripta Mater. 2013, 
vol. $68,162-65$.

2 [15] B.B. He, W. Xu and M.X. Huang: Mater. Sci. Eng. A 2014, vol. 609, 141-46.

3 [16] Y.C. Liu, D.J. Wang, F. Sommer and E.J. Mittemeijer: Acta Mater. 2008, vol. 56,

4 3833-42.

[17] H.J. Hu, G. Xu, L. Wang, M.X. Zhou and Z.L. Xue: Met. Mater. Int. 2015, vol. 21, pp. 929-35.

[18] L.C. Chang and H.K.D.H. Bhadeshia: Mater. Sci. Eng. A 1994, vol. 184, pp. 17-19.

[19] G. Xu, H. Zou and C.H. Bu: Adv. Mater. Res. 2011, vol. 415, pp. 974-78.

[20] J.G. He, A.M. Zhao, C. Zhi and H.L. Fan: Scripta Mater. 2015, vol. 107, pp. 71-74.

[21] H.J. Hu, H.S. Zurob, G. Xu, D, Embury and G.R. Purdy: Mater. Sci. Eng. A 2015, vol. 626 , pp. 34-40.

[22] H.J. Hu, G. Xu, L. Wang and M.X. Zhou: Steel Res. Int. 2016, DOI: $10.1002 /$ srin.201600170.

[23] G.H. Chen, G. Xu, H.J. Hu, Q. Yuan and Q.X. Zhang: Steel Res. Int. 2018, DOI: 10.1002/srin.201800201.

[24] M.T. Todinov, J.F. Knott and M. Strangwood: Acta Mater. 1996, vol. 44, 4909-15.

[25] J.R. Patel and M. Cohen: Acta Metall. 1953, vol. 1, 531-38.

[26] J.X. Wu, B.H. Jiang and T.Y. Hsu: Acta Metall. Sin. 1988, vol. 36, 1521-26.

[27] Y. Tian, A. Borgenstam and P. Hedström: J. Alloys Compd. 2018, vol. 766, pp. 

131-39.

2 [28] X.D. Zhang, J.Q. Ren and X.D. Ding: Appl. Compos. Mater. 2018, DOI: $3 \quad 10.1007 / \mathrm{s} 10443-018-9701-5$.

4 [29] M. Eskandari, M.A. Mohtadi-Bonab, A. Zarei-Hanzaki, A.G. Odeshi and J.A. 5 Szpunar: J. Mater. Eng. Perform. 2016, vol. 25, pp. 1611-20.

6 [30] M.F. Ashby: Philos. Mag. A 1970, vol. 21, pp. 399-24.

7 [31] A. Kundu and D.P. Field: Metall. Mater. Trans. A 2018, vol. 49, pp. 3274-82.

8 [32] T. Song and B.C.D. Cooman: ISIJ Int. 2014, vol. 54, pp. 2394-03.

9 [33] S. Dash and N. Brown: Acta Metall. 1966, vol. 14, pp. 595-03.

[34] L. Samek E.D. Moor, J. Penning, and B.C.D. Cooman: Metall. Mater. Trans. A 2006, vol. 37, pp. 109-124. 
Table 1 The measured PAG of different deformed samples

\begin{tabular}{cccc}
\hline Deformation & \multicolumn{3}{c}{ Strain amount } \\
\cline { 2 - 4 } temperature & $\mathbf{0 . 0 5}$ & $\mathbf{0 . 1 5}$ & $\mathbf{0 . 5 0}$ \\
\hline $300{ }^{\circ} \mathbf{C}$ & $24.2 \pm 3.1$ & $17.6 \pm 2.5$ & $11.6 \pm 1.4$ \\
$600{ }^{\circ} \mathbf{C}$ & $18.4 \pm 1.8$ & $13.1 \pm 1.4$ & $9.5 \pm 1.7$ \\
$860{ }^{\circ} \mathbf{C}$ & $13.4 \pm 2.3$ & $10.3 \pm 1.7$ & $6.2 \pm 1.5$ \\
\hline
\end{tabular}

3 


\section{Figures captions}

2 Fig. 1 Experimental procedure

3 Fig. 2 Example of dilatation change with temperature during the whole process: (a)

$4 \quad 600{ }^{\circ} \mathrm{C}+0.05$ strain specimen; and (b) non-deformation specimen

5 Fig. 3 The change of stress during the whole simulation test for specimen with 0.15

6 strain at $300{ }^{\circ} \mathrm{C}$, illustrating the little influence of stress on $\mathrm{M}_{\mathrm{S}}$ during cooling process

$7 \quad$ Fig. 4 Temperature-dilatation curves illustrating the $M_{S}$ of different specimens: (a)

8 without deformation; (b) $300{ }^{\circ} \mathrm{C}+0.05$ strain; (c) $600{ }^{\circ} \mathrm{C}+0.05$ strain; and (d)

$9 \quad 860{ }^{\circ} \mathrm{C}+0.05$ strain

Fig. 5 The change of $M_{S}$ with strain amount and ausforming temperature

Fig. 6 The relationship between $M_{S}$ and $d^{-1 / 2}$ according to Hall-Petch formula

Fig. 7 Examples of PAG for samples deformed at $860{ }^{\circ} \mathrm{C}$ with different strain amount:
(a) 0.05 ;
(b) 0.15 ; and (c) 0.50

Fig. $8 \mathrm{M}_{\mathrm{S}}$ change following the parabola law at the strain before reaching the $\varepsilon_{s}$

Fig. 9 Stress-strain curves of the specimens deformed at 300, 600 and $860{ }^{\circ} \mathrm{C}$, indicating no dynamic recrystallization happened

Fig. 10 The $\mathrm{OM}$ microstructure of different specimens: (a) $300{ }^{\circ} \mathrm{C}+0.05$ strain; (b) $300{ }^{\circ} \mathrm{C}+0.50$ strain; (c) $600{ }^{\circ} \mathrm{C}+0.05$ strain; (d) $600{ }^{\circ} \mathrm{C}+0.50$ strain; (e) $860{ }^{\circ} \mathrm{C}+0.05$ strain; and (f) $860{ }^{\circ} \mathrm{C}+0.50$ strain

Fig. 11 The SEM microstructure of specimens treated by different processes: (a) without deformation; (b) $300{ }^{\circ} \mathrm{C}+0.05$ strain; (c) $300{ }^{\circ} \mathrm{C}+0.15$ strain; (d) $300{ }^{\circ} \mathrm{C}+0.50$ strain; (e) $860{ }^{\circ} \mathrm{C}+0.05$ strain; (f) $860{ }^{\circ} \mathrm{C}+0.15$ strain; and (g) $860{ }^{\circ} \mathrm{C}+0.50$ strain Fig. 12 The Vicker's hardness of specimens 